\title{
Trends and gender differences in age at sex debut among adolescents and young adults in urban Cape Area, South Africa
}

\author{
Evans Muchiri, Clifford Odimegwu
}

Demography and Population Studies Programme, Schools of Public Health and Social Sciences, University of the Witwatersrand, Johannesburg, South Africa

\begin{abstract} sexual debut. munity factors. adults' development context.

DOI: https://dx.doi.org/10.4314/ahs.v19i4.17

\section{Introduction}

Initiation into sexual activity among adolescents and young adults is an important marker of transition into adulthood and is usually embedded with social and personal meanings ${ }^{1,2}$. Early age at first sex (before 15 years as per WHO definition) exposes an adolescent to the risk of unwanted pregnancy and HIV infection alongside other sexually transmitted disease ${ }^{3-6}$. Among teenagers in the US, age at first sex has steadily decreased since the 1980, and the proportion reporting sex before the age of 15 has been on the rise ${ }^{7}$. In South Africa, reports indicate that early sex debut is a major contributor to disease and disability among the youths, as calculated through disability-adjusted life years ${ }^{6,8,9}$. Understanding circumstances of early sexual debut among adolescents and young adults
\end{abstract}

Background: Adolescents and young adults in South Africa are at increased risk of experiencing negative outcomes from early sex initiation due to the context they develop in. This study aimed at investigating trends and gender differences in early age at

Methods: Data from the Cape Area Panel Study (CAPS) of young adults' conducted between 2002 and 2009 in urban Cape Town were used. Correlates of early sex using ecological risk factors were analysed.

Results: Overall mean age at sexual debut at follow-up was 17.5 years (standard deviation (SD) =2.5), with males at 16.8 years $(\mathrm{SD}=2.5)$ and 18.1 years $(\mathrm{SD}=2.4)$ for females. Males consistently reported an earlier age at sex debut across the five waves of the survey. Significant risk factors for early sex appeared at all levels of the ecology to include individual, household, and com-

Conclusions: Integrated interventions for delaying early sex debut should consider factors within the ecology of the young

Keywords: Sex debut, adolescents and young adults, contextual risk factors, cumulative risk.

Cite as: Muchiri E, Odimegwu C. Trends and gender differences in age at sex debut among adolescents and young adults in urban Cape Area, South Africa. Afri Health Sci.2019;19(4):2964-2972.https:// dx.doi.org/10.4314/abs.v19i4.17

\section{Corresponding author: \\ Evans Muchiri, \\ Demography and Population Studies \\ Programme, Schools of Public Health \\ and Social Sciences, University of the \\ Witwatersrand, Johannesburg, South Africa \\ Email: EMuchiri@live.co.uk}

has important implications for theory, policy and practice. South Africa has the highest number of people living with HIV (PLHIV) of any country in the world as of 2016 with an estimated 7.1 million PLHIV and young people are disproportionally affected ${ }^{10}$. Even though South African youth make less than $1 \%$ of the world's youth, the country accounts for more than $15 \%$ of global youths living with HIV. At the same time, South Africa has one of the highest rates of teenage pregnancies around the globe. More than $35 \%$ of adolescents reportedly become pregnant before the age of 20 years with more than 30\% giving birth at least once ${ }^{11-13}$. Even though a high rate of school resumption and completion has been reported for teenage mothers in South Africa compared to other countries of sub-Saharan Africa, disruption from schooling is associated with truncated educational attainment and lower future economic returns ${ }^{14-16}$. Furthermore, early childbearing put young women at risk of morbidity and mortality resulting from birth complications ${ }^{17-19}$.

Studies reporting on determinants of early sex debut have found variation in rural-urban residence, race, socio-economic status, academic performance, and peer influence on adolescent's sexual debut ${ }^{20-23}$. In South Africa, 
it is reported that males begin sexual activity earlier than females, and young adults of the Black/African race begin sexual activity at a significantly younger age compared to the Whites or Coloureds ${ }^{24}$. Other studies have reported on ecological factors that inform on adolescents' decision to engage in early sexual activities including family composition, staying with a single parent, parental supervision, perceved risk of STIs, available community health facilities, and media influence ${ }^{22,25}$. In addition, lower family incomes, living in disadvantaged neighbourhoods, lacking parental supervision, and community permissive attitudes have also been reported ${ }^{24,26}$. However, many of these findings emanate from studies conducted in developed countries, and even then, the contribution of risk factors has been reported in isolation.

In this study, we report findings of using an ecological perspective framework to investigate trends and gender differences in early sex activities. The ecological systems framework as proposed by Bronfenbrenner (1979), groups risk factors into the individual, household, and the community levels. The cumulative risk approach as proposed by Small and Luster (1994) is tested to study whether the effect of ecological risk factors is cumulative ${ }^{27-29}$. Using this approach, it is assumed that risk factors occurring at the multiple levels of the ecology act cumulatively to influence an adolescent' sexual behaviours, rather than risk factors acting in isolation30. Understanding circumstances of initiating into sexual activity is important, because it may be forced, and is a potential hazard for pregnancy and disease transmission ${ }^{1,2}$

\section{Data and methods}

\section{Study design}

The Cape Area Panel Study (CAPS) was a longitudinal survey of young adults in urban Cape Town that was conducted as a collaborative project of the University of Michigan and the University of Cape Town. The CAPS was conducted in waves 1 to 5 between 2002 and 2009 by the time of these analyses. The CAPS sampling plan was designed to produce a young adult sample that was representative of the population aged between 14 and 22 years-old in metropolitan Cape Town. The surveys were conducted in waves with the first wave conducted between August and December, 2002. A third of the adolescents were again interviewed in 2003 (2a), and the remaining two-thirds re-visited in 2004 (wave 2b). The full youth sample was again re-interviewed in 2005 (wave 3) and 2006 (wave 4). The last wave was a face-to-face interview of any youth interviewed previously and was conducted in 2009 (wave 5).

\section{Participants and setting}

An estimated 4,800 young adults aged between 14 and 22 years were randomly selected and interviewed in the first wave of the CAPS survey conducted in 2002. The survey also collected information on all members of these young people's households. Additionally, a random sample of households that did not have members of the age grop 14 to 22 years was also interviewed. The young adults were followed-up in successive surveys with the latest conducted in 2009. The study was conducted in metropolitan area of the City of Cape Town in the Western Cape province of South Africa.

\section{Procedures}

Questionnaires were administered to the adolescents and young adults to collect current and retrospective data about themselves, their households, and their communities. Data are captured in the form of modules detailing life-history, schooling, employment, sexual behaviours, and family relationships.

\section{Outcome measures}

Early age at sex debut was the dependent variable in this study and was defined as sex intercourse before the age of 15 years. In the CAPS surveys, young adults reporting sexual activity also reported age at firs sex. We restricted our outcome to only young adults transitioning into sexual activity during follow-up to establish a causal relationship between baseline risk factors and onset of early sexual activity.

\section{Risk factors}

Baseline risk factors are categorised into the individual, household, and community levels. At the individual level, factors reported included race, school achievements and aspirations, history of sexual abuse, marital status, employment, family size, ability to make personal decisions on health, and knowledge of HIV/AIDS. At the household level, risk factors included socio-economic status of the family, living with single or both parents, parental monitoring and supervision, closeness to the parents, and parents' education attainment. At the community level, mean age at marriage for men and women, socio-economic profile of the community including proportion of employed and education status of men and women. 
Furthermore, knowledge and attitudes towards HIV, religiosity, graduation rates, peer influence, and availability of health facilities in the community will be considered.

\section{Statistical analysis}

Statistical analysis and data manipulation were carried out in STATA version 13 (STATA Corporation, College Station, TX). Proportions, means and standard deviations were used to summarize the data, while cross-tabulations and Chi-square tests were applied for differences between bivariate categorical groups with associated p-values reported. For multivariate analysis, discriminant function analysis (DA) was used to describe and classify participants into early and late sexual debutants groups. Assumptions of the DA were met as the sample was randomly selected thus independence of the observations, multivariate normality of the observations, and equal covariance matrices for the two groups under investigations. A test of differences between the categorical outcome and multivariate predictor variables used the F-value tests of significance where resulting $\mathrm{p}$-values were reported. A cumulative risk index was constructed by summing the number of risk factors that were found to be significant in the discriminant analyses. The proportion of sexually active young people was plotted against the number of risk factors reported to determine the effect of increasing risk factors on engaging in early sex debut. These analyses were performed separately for males and females, with risk factors occurring at the individual, household, and community levels.

\section{Ethical issues}

This study used CAPS datasets and has acknowledged the CAPS survey team at the Centre for Social Science Research, University of Cape Town.

\section{Results}

Of the 4,704 adolescents and young adults responding to the young adult questionnaire by wave 1 survey of 2002, a total of 2,162 (46\%) reported to have experienced sexual debut and were excluded from further analysis. Out of the 2,542 adolescents who were sexually inexperienced at baseline, 1,712 (67.4\%) transitioned into sexual activity by wave 5 survey of 2009. Overall mean age at sexual debut at follow-up was 17.5 years $(\mathrm{SD}=2.5)$, with males at 16.8 years $(\mathrm{SD}=2.5)$ and 18.1 years $(\mathrm{SD}=2.4)$ for females. Table 1 and Table 2 report on the descriptive statistics of the analysis sample separately conducted for males and females.

Table 1: Trends in sexual and reproductive health outcomes for males

\begin{tabular}{|l|l|l|l|l|l|}
\hline Males & $\begin{array}{l}\text { Wave } \\
1(\mathrm{n}=2,114)\end{array}$ & $\begin{array}{l}\text { Wave } \\
2(\mathrm{n}=623)\end{array}$ & $\begin{array}{l}\text { Wave } \\
3(\mathrm{n}=1574)\end{array}$ & $\begin{array}{l}\text { Wave } \\
4(\mathrm{n}=1,485)\end{array}$ & $\begin{array}{l}\text { Wave } \\
5(\mathrm{n}=1,263)\end{array}$ \\
\hline Sexually Experienced (n, \%) & $967(46 \%)$ & $413(66 \%)$ & $1,165(74 \%)$ & $1,247(84 \%)$ & $1,205(95 \%)$ \\
\hline Age at Sexual Initiation (Mean, SD) & $15.7(1.8)$ & $15.6(1.7)$ & $16.0(1.9)$ & $16.0(2.0)$ & $18.3(3)$ \\
\hline Willing to have first sex*, $\mathrm{n}(\%)$ & $926(96 \%)$ & $301(94 \%)$ & $1,037(96 \%)$ & $\mathrm{n} / \mathrm{r}$ & $\mathrm{n} / \mathrm{r}$ \\
\hline Always used condom last sex*, $(\%)$ & $469(71.6 \%)$ & $195(77.4 \%)$ & $\mathrm{n} / \mathrm{r}$ & $\mathrm{n} / \mathrm{r}$ & $\mathrm{n} / \mathrm{r}$ \\
\hline MSP in last 12 months*, $(\%)$ & $401(50 \%)$ & $\mathrm{n} / \mathrm{r}$ & $265(29 \%)$ & $398(43 \%)$ & $415(41 \%)$ \\
\hline Use protection at last Sex*, n (\%) & $692(77 \%)$ & $267(77 \%)$ & $780(77 \%)$ & $769(74 \%)$ & $793(72 \%)$ \\
\hline Made someone pregnant (n, \%) & $123(6 \%)$ & $\mathrm{n} / \mathrm{r}$ & $260(16 \%)$ & $331(21 \%)$ & $\mathrm{n} / \mathrm{r}$ \\
\hline Age of first sex partner (mean) & 15.3 & 15.7 & & 15.8 & 18.5 \\
\hline
\end{tabular}

Key: *\% based on non-missing responses, $n / r$ not reporting 
For males, sexual experience was reported at $46 \%$ at Wave 1 survey increasing to $95 \%$ by the Wave 5 survey as reported in Table 1. Majority of males reported to have had consensual sex relationships throughout the surveys, with $96 \%$ of males reporting sexual experience at baseline, having been willing to have first sex.

Table 2: Trends in sexual and reproductive health outcomes for females

\begin{tabular}{|c|c|c|c|c|c|}
\hline Females & $\begin{array}{l}\text { Wave } \\
1(n=2590)\end{array}$ & $\begin{array}{l}\text { Wave } \\
2(n=745)\end{array}$ & $\begin{array}{l}\text { Wave } \\
3 \quad(n=1,852)\end{array}$ & $\begin{array}{l}\text { Wave } \\
4(n=1,806)\end{array}$ & $\begin{array}{l}\text { Wave } \\
5 \quad(n=1,560)\end{array}$ \\
\hline Sexually experienced (n, \%) & $1,195(46 \%)$ & $468(63 \%)$ & $1,343(73 \%)$ & $1,488(82 \%)$ & $1,456(93 \%)$ \\
\hline Age at sexual initiation (Mean, SD) & $16.6(1.7)$ & $16.5(1.7)$ & $16.9(1.9)$ & $17(1.9)$ & $20.2(2.2)$ \\
\hline Willing to have first sex*, n (\%) & $1,010(85 \%)$ & $383(82 \%)$ & $1,114(83 \%)$ & $\mathrm{n} / \mathrm{r}$ & $\mathrm{n} / \mathrm{r}$ \\
\hline Always used condoms last sex*, n (\%) & $405(66.2 \%)$ & $218(77.3 \%)$ & & & \\
\hline MSP in last 12 months* (n, \%) & $198(19 \%)$ & $\mathrm{n} / \mathrm{r}$ & $89(8 \%)$ & $150(12 \%)$ & $162(13 \%)$ \\
\hline Use protection at last $\operatorname{sex} *(\mathrm{n}, \%)$ & $766(68 \%)$ & $303(73 \%)$ & $871(70 \%)$ & $896(66 \%)$ & $926(67 \%)$ \\
\hline Ever been pregnant* (n, \%) & $443(17 \%)$ & $\mathrm{n} / \mathrm{r}$ & $675(35 \%)$ & $826(44 \%)$ & $\mathrm{n} / \mathrm{r}$ \\
\hline Age of first sex partner (mean) & 19.6 & 19.5 & & 20.2 & 22.8 \\
\hline
\end{tabular}

Key: *\% based on non-missing responses - denominator not reported, $n / r$ not reporting

Similar trends were observed for females, with sexual experience at Wave 1 survey reported at 46\%, increasing to $93 \%$ by Wave 5 as shown in Table 2 . A substantial proportion of female respondents reported coerced or forced first sex activity, with 15\% reporting not willing to have first sex. Willingness to have first sex slightly differs by gender, where a higher proportion of males compared to females, reported consenting to first sex. The mean age at first sex for males was 15.7 (SD 1.8) years for females and 16.6 (SD 1.7) years for females at Wave 1, implying that males became sexually experienced at a younger age compared to females. Figure 1 shows that over the follow-up, males consistently reported lower average age at first sex.



Figure 1: Mean age at sexual debut at baseline and follow-up 
Table 3: Baseline characteristics of young adult respondents and transitions into sexual activity

\begin{tabular}{|c|c|c|c|c|c|}
\hline Individual level variables & $\begin{array}{l}\text { All young } \\
\text { adults } \\
(\mathrm{n}=4,704)\end{array}$ & $\begin{array}{l}\text { Sexually } \\
\text { inexperienced at } \\
\text { baseline } \\
(\mathrm{n}=2,542) \\
\end{array}$ & $\begin{array}{l}\text { Late Sexual } \\
\text { Debut at follow- } \\
\text { up }(n=1,615)\end{array}$ & $\begin{array}{l}\text { Early Sexual } \\
\text { Debut at follo } \\
\text { w-up }(n=140)\end{array}$ & P-Value* \\
\hline Male sex, n (\%) & $2,114(45)$ & $1,147(45)$ & $622(42)$ & $103(74)$ & $<0.01$ \\
\hline Black Africans, n (\%) & $2,144(46)$ & $823(32)$ & $548(37)$ & $97(69)$ & $<0.01$ \\
\hline Years of Education,(Mean, SD) & $9.5(2.8)$ & $9.0(2.7)$ & $8.9(2.3)$ & $7.7(1.9)$ & $<0.01$ \\
\hline Expects to pass Matric, $\mathrm{n}(\%$ yes $)$ & $2,701(73)$ & $1,727(81)$ & $1,015(88)$ & $110(90)$ & 0.89 \\
\hline Worked in last 12 months, $\mathrm{n}$ (\% yes) & $1,316(28)$ & $592(23)$ & $318(22)$ & 10(7) & $<0.01$ \\
\hline Highly expects to work in 3 years, $n(\%)$ & $2,093(47)$ & $1,060(44)$ & $613(44)$ & $26(20)$ & $<0.01$ \\
\hline \multicolumn{6}{|l|}{ Household level variables } \\
\hline Number of siblings (Median, IQR) & $2(1,3)$ & $2(1,3)$ & $2(1,3)$ & $2(1,3)$ & 0.39 \\
\hline Parents married, n (\% yes) & $3,527(76)$ & $1,970(78)$ & $1,103(75)$ & $97(69)$ & 0.11 \\
\hline Mother often spend time with YA, n (\%) & $2,848(65)$ & $1,700(71)$ & $972(70)$ & $89(69)$ & 0.79 \\
\hline Father often spends time with YA, n (\%) & $1,630(42)$ & $1,066(48)$ & $582(46)$ & $48(40)$ & 0.22 \\
\hline Brother /Sister helps with study, n (\%) & $756(16)$ & $454(18)$ & $258(18)$ & $30(21)$ & 0.25 \\
\hline HH meals in a day (Mean, SD) & $3.7(0.5)$ & $3.8(0.4)$ & $3.8(0.5)$ & $3.8(0.4)$ & 0.70 \\
\hline Influence on future job (Median, IQR) & $1(1,3)$ & $1(1,3)$ & $1(1,3)$ & $1(1,2)$ & 0.20 \\
\hline \multicolumn{6}{|l|}{ Community level variables } \\
\hline \% HH Unemployed (Median, IQR) & $16(8,30)$ & $13(6,27)$ & $15(9,27)$ & $28(14,33)$ & $<0.01$ \\
\hline$\%$ HH female headed (Median, IQR) & $40(32,45)$ & $38(31,45)$ & $40(32,45)$ & $41(36,47)$ & 0.02 \\
\hline \%HH Informal dwelling (Median, IQR) & $2(0,42)$ & $1(0,4)$ & $1(0,11)$ & $11(1,48)$ & $<0.01$ \\
\hline $\begin{array}{l}\% \mathrm{HH} \text { Individuals Africans (Median, } \\
\text { IQR) }\end{array}$ & $10(3,99)$ & $4(2,99)$ & $4(2,99)$ & $99(9,99)$ & $<0.01$ \\
\hline Mean years of schooling (Median, IQR) & $\begin{array}{l}8.9(8.4,10 . \\
0)\end{array}$ & $9.1(8.5,10.5)$ & $8.8(8.4,9.8)$ & $8.9(8.5,9.6)$ & 0.58 \\
\hline $\begin{array}{l}\% \text { HH below Poverty Line (Median, } \\
\text { IQR) }\end{array}$ & $23(14,44)$ & $18(6,34)$ & $22(14,44)$ & $44(22,48)$ & $<0.01$ \\
\hline
\end{tabular}

* P-value comparing early and late sexual debut, $\mathrm{YA}$ =young adult, $\mathrm{HH}=$ Household. Based on non-missing responses

Findings from these analyses indicate that males consistently initiate sexual activity at a younger age compared to females, reporting a mean age of 15.7 years for males and 16.6 years for females at Wave 1 , and 18.3 years for males and 20.2 years for females at Wave 5 survey. For their sexual partners, at Wave 1 survey, sexually experienced males reported a mean age of 15.3 years, with females reporting 19.6 years. This indicates that males were on average engaging in sexual activity with younger partners, while females were engaging with slightly older partners. Differences in age of first sexual partner were significant for males and females throughout the five surveys. In terms of early sex, $21.7 \%$ of male and $9.5 \%$ of female respondents were classified to have experienced early sexual activity, a difference that was significant $(p<0.01)$.
The majority of respondents consented to first sex, with $96.1 \%$ of males and $84.8 \%$ of females at the Wave 1 survey. During Wave 5 survey, $98 \%$ of males, and $95 \%$ of females reported to have consented to their first sexual intercourse. Females were more likely to have first sex with their boyfriends at $93.2 \%$, compared to males having sex with girlfriends at $81 \%$, suggesting that casual relationships were more frequent in males than females. Further, $51 \%$ of males and $54 \%$ of females protected themselves against disease or pregnancy at first sex. Condoms were commonly used at first sex with $89 \%$ males and $75 \%$ females reporting condom use to protect from disease and unwanted pregnancy. Females were more likely to stay longer in their first sexual relationships with an average of 6.4 months compared to males at 5.4 months, as re- 
ported in Wave 1. In summary, many of the independent factors were significantly different between males and females, and further analysis were conducted stratified by gender.

\section{Correlates of early sexual activity}

Further analyses were conducted for adolescents and young adults who were not sexually experienced at baseline, and were followed-up to monitor transitioning into sexual activity by the end of the wave 5 survey. Of the 1,712 adolescents experiencing sexual debut during follow-up, 1,615 had non-missing age at first sex and were used for these analyses, with 140 (9\%) reporting early sexual activity. Early sexual debut significantly differed by gender, with $14 \%$ of males reporting early sex compared to $4 \%$ of females $(\mathrm{p}<0.01)$. A significantly higher proportion of African blacks reported early sexual debut at $15 \%$ compared to Coloured at $4.6 \%$ and Whites at 3.6\% $(\mathrm{p}<0.01)$. Table 3 reports on transitions into sexual activity of the adolescent and young adults' sample.

Significant individual level risk factors for sexual transitions included gender, population group, years of schooling, having worked in the last year, and expecting to work in the future. At the community level, households' employment, female headed households, dwelling in informal settings, households with African population, and households reporting to be below poverty lines. Table 4 reports on means and standardised scores from Discriminant analyses for considered risk factors.

Table 4: Means and Standardized Discriminant Function Coefficient for Early Sexual Debut

MALES

FEMALES

\begin{tabular}{|c|c|c|c|c|c|c|c|c|c|c|}
\hline Independent Variables & $\begin{array}{l}\text { Late } \\
\text { Sexual } \\
\text { Debut }\end{array}$ & $\begin{array}{c}\text { Early } \\
\text { Sexual } \\
\text { Debut }\end{array}$ & F-Value & P-value & $\mathrm{LD}^{*}$ & $\begin{array}{l}\text { Late } \\
\text { Sexual } \\
\text { Debut }\end{array}$ & $\begin{array}{l}\text { Early } \\
\text { Sexual } \\
\text { Debut }\end{array}$ & $\begin{array}{l}\text { F- } \\
\text { Value }\end{array}$ & $\begin{array}{l}\mathrm{P}- \\
\text { value }\end{array}$ & $\mathrm{LD}^{*}$ \\
\hline \multicolumn{11}{|l|}{ Individual } \\
\hline $\begin{array}{l}\text { Population group } \\
(1=\text { Black, } 2=\text { Others })\end{array}$ & 1.67 & 1.30 & 28.17 & $<0.01$ & & 1.59 & 1.32 & 8.31 & $<0.01$ & \\
\hline $\begin{array}{l}\text { Years of Education } \\
\text { (mean years, SD) }\end{array}$ & $\begin{array}{l}8.62 \\
(2.45)\end{array}$ & $\begin{array}{l}7.66 \\
(2.00)\end{array}$ & 7.51 & $<0.01$ & 0.19 & $\begin{array}{l}9.12 \\
(2.30)\end{array}$ & $\begin{array}{l}7.78 \\
(1.76)\end{array}$ & 6.15 & $<0.01$ & -0.38 \\
\hline $\begin{array}{l}\text { Currently in school } \\
(1=\text { Yes, } 2=\mathrm{No})\end{array}$ & 1.19 & 1.22 & 2.00 & 0.14 & & 1.17 & 1.13 & 4.22 & 0.02 & \\
\hline $\begin{array}{l}\text { Plans to pass Matric one } \\
\text { time }(1=\text { Yes, } 2=\text { No })\end{array}$ & 1.08 & 1.08 & 0.06 & 0.93 & & 1.06 & 1.03 & 1.52 & 0.22 & \\
\hline Age of first sex partner & $\begin{array}{l}17.0 \\
(2.73)\end{array}$ & $\begin{array}{l}13.4 \\
(2.37)\end{array}$ & 63.54 & $<0.01$ & -0.96 & $\begin{array}{l}20.81 \\
(3.75)\end{array}$ & $\begin{array}{l}17.73 \\
(3.31)\end{array}$ & 11.14 & $<0.01$ & -0.66 \\
\hline $\begin{array}{l}\text { Worked in the last } 12 \\
\text { months }(1=\text { Yes, } 2=\mathrm{No})\end{array}$ & 1.73 & 1.91 & 7.48 & $<0.01$ & & 1.82 & 1.97 & 5.11 & $<0.01$ & \\
\hline Religious $(1=$ yes, $2=$ No $)$ & 1.69 & 1.78 & 2.61 & 0.07 & & 1.63 & 1.69 & 3.75 & 0.41 & \\
\hline \multicolumn{11}{|l|}{ Household } \\
\hline $\begin{array}{l}\text { Number of siblings } \\
\text { (Mean, SD) }\end{array}$ & $2.04(1.5)$ & $\begin{array}{l}2.20 \\
(1.7)\end{array}$ & 1.67 & 0.19 & & $\begin{array}{l}2.14 \\
(1.6)\end{array}$ & $\begin{array}{l}2.48 \\
(2.0)\end{array}$ & 4.62 & 0.01 & \\
\hline $\begin{array}{l}\text { Parents married }(1=\mathrm{Yes}, \\
2=\mathrm{No})\end{array}$ & 1.21 & 1.29 & 2.44 & 0.08 & & 1.26 & 1.35 & 4.40 & 0.01 & -0.11 \\
\hline $\begin{array}{l}\text { Mother often spend time } \\
\text { with young adult }\end{array}$ & $5.10(2.2)$ & $\begin{array}{l}4.86 \\
(2.2)\end{array}$ & 1.24 & 0.29 & & $5.19(2.1)$ & $\begin{array}{l}5.88 \\
(1.6)\end{array}$ & 6.10 & $<0.01$ & \\
\hline $\begin{array}{l}\text { Father often spends time } \\
\text { with young adult }\end{array}$ & $3.96(2.4)$ & $\begin{array}{l}3.45 \\
(2.6)\end{array}$ & 2.61 & 0.07 & & $3.64(2.5)$ & $3.6(2.5)$ & 2.39 & 0.09 & \\
\hline $\begin{array}{l}\text { Brother or sister helps } \\
\text { with homework }\end{array}$ & 1.83 & 1.77 & 2.04 & 0.13 & & 1.81 & 1.81 & 3.88 & 0.02 & \\
\hline $\begin{array}{l}\text { Meals in a day in the } \\
\text { household (Mean, SD) }\end{array}$ & $3.81(0.5)$ & $\begin{array}{l}3.83 \\
(0.5)\end{array}$ & 0.77 & 0.45 & & $3.81(0.4)$ & $3.83(0.4)$ & 3.86 & 0.02 & \\
\hline $\begin{array}{l}\text { Most influence on future } \\
\text { job (Mean, SD) }\end{array}$ & $2.29(2.6)$ & $2.43(2.5)$ & 1.14 & 0.32 & & $2.32(2.5)$ & $1.89(2.0)$ & 4.44 & 0.01 & \\
\hline \multicolumn{11}{|l|}{ Community } \\
\hline $\begin{array}{l}\text { \% HH Unemployed } \\
\text { (Mean ) }\end{array}$ & $0.16(0.1)$ & $0.25(0.1)$ & 44.8 & $<0.01$ & -0.51 & $0.18(0.1)$ & $0.23(0.1)$ & 6.13 & 0.01 & -0.83 \\
\hline $\begin{array}{l}\text { \% HH headed by females } \\
\text { (Mean) }\end{array}$ & $0.39(0.1)$ & $0.42(0.1)$ & 8.08 & $<0.01$ & -0.13 & $0.40(0.1)$ & $0.41(0.1)$ & 0.07 & 0.77 & \\
\hline $\begin{array}{l}\% \mathrm{HH} \text { in Informal } \\
\text { dwelling (Mean) }\end{array}$ & $0.13(0.2)$ & $0.27(0.3)$ & 24.24 & $<0.01$ & -0.25 & $0.16(0.3)$ & $0.26(0.3)$ & 4.38 & 0.04 & \\
\hline $\begin{array}{l}\% \mathrm{HH} \text { Individuals } \\
\text { Africans (Mean ) }\end{array}$ & $0.34(0.4)$ & $0.71(0.4)$ & 60.96 & $<0.01$ & 0.24 & $0.41(0.5)$ & $0.68(0.5)$ & 12.05 & $<0.01$ & 0.91 \\
\hline $\begin{array}{l}\% \text { HH below Poverty } \\
\text { Line (Mean ) }\end{array}$ & $0.25(0.2)$ & $0.38(0.1)$ & 52.75 & $<0.01$ & 0.68 & $0.27(0.2)$ & $0.35(0.2)$ & 7.74 & 0.01 & 0.12 \\
\hline
\end{tabular}

*LD - Linear Discriminant function coefficients 
Table 4 reports on results from the multivariate analyses on factors discriminating against early age at sexual debut. In males, significant factors at the individual level included; population group, years in education, age of first sex partner, and having worked in the last year. At the household level, parents ever married, and father spending time in the household were mildly important but had no statistically significant effect on early sexual debut. Significant community factors included employment levels, female headed households, and informal dwellings in the community, poverty levels, and proportion of families classified as Africans. Nine risk factors were selected, and only seven were found to contribute significantly to the group classification in the multivariate analysis. Age of first sex partner and years in education were important factors at the individual level, while proportion of unemployed households' heads, informal dwellings, households headed by a female, households with individual Africans, and families below poverty line were major determinants at the community level.

For females, individual level factors discriminating early sexual debut included years of education, population group, currently being in school, age of first sex partner, and having worked in the last year. At the household level, number of siblings, parents married, spending time with the mother, siblings who helped with homework, number of meals in day, and most influence on future jobs. At the community level, proportion of household heads unemployed, living in informal dwellings, proportion of the community below poverty level, and proportion of households classified as black Africans had significant effect on early sexual activity. Six risk factors were found to discriminate significantly the group classification in the multivariate analyses. At the individual level, age of first sex partner and years in education were important, while only parents ever married was significant at the household level. The proportion of unemployed household heads, proportion of household with individual Africans, and proportion of households below poverty line were important at the community level.

\section{Discussion}

Previous studies reporting on age at first sex have identified slight gender differences at mean age of first sex, with males becoming sexually experienced much earlier compared to females ${ }^{8,31-33}$. Pettifor et al observed that among 15-19 year old respondents from a nationally representa- tive survey in South Africa, $50 \%$ of males, and $47 \%$ of females reported ever having sex ${ }^{34}$. Further, reporting that mean age at first sex was at 16.4 years for males, and 16.8 years for females, findings that were consistent with this study. However, this study does not identify substantial gender differences in terms of sexual experience at both Wave 1 and Wave 5. Findings from the current study on trends and genders differences may indicate an increase in the age of sex debut and are consistent with other reported studies ${ }^{35}$.

Contrary to previous findings where gender inequality for young women was manifested through sexual coercion and partnering with older men, these findings suggest that young women in South Africa mainly had first sex with partners of similar age ${ }^{36}$. Reported sexual partner at first sex was mainly the boyfriend or girlfriend of the respondent, reporting $88 \%$ of all the time. Majority of females had first sex in committed relationships either in marriage, or when engaged to partners or living together. Therefore, safe sexual messages could be targeted to schooling institutions, mainly targeting similar age-group relationships as these are more frequently exercised and have the potential to be most effective in delaying sex debut. In summary, for school attending respondents, their first sexual partners were likely to be their girlfriends or boyfriends in the same age group and could be targeted with appropriate interventions.

\section{Limitations}

These data lacked important indicators of peer influence, which might further explain on findings of sexual relationships among respondents of the same age group. In addition, studies of sexual behaviours may be prone to social desirability biases that may distort responses, differences that may be exacerbated by gender of respondents.

\section{Conclusion}

This study finds that a high proportion of adolescents were initiating sexual activity at an early age and that gender differences in early sex persisted throughout the study period. Other important indicators of early sexual debut identified were age of first sex partner, population group, years in education, and markers of community socio-economic status. These findings have also been previously reported in studies conducted in South Africa and other developed countries ${ }^{13,37}$. The presence of risk factors at 
multiple levels of the ecology suggests that interventions aimed at delaying early sexual debut should not only target individual attributes but also both the household and community context.

This study was significant in that analysing ecological factors for early sexual activities adds significantly informs on interventions to improve on sexual and reproductive health outcomes for adolescents and young adults in South Africa.

\section{Acknowledgement}

The Cape Area Panel Study Waves 1-2-3 were collected between 2002 and 2005 by the University of Cape Town and the University of Michigan, with funding provided by the US National Institute for Child Health and Human Development and the Andrew W. Mellon Foundation. Wave 4 was collected in 2006 by the University of Cape Town, University of Michigan and Princeton University. Major funding for Wave 4 was provided by the National Institute on Aging through a grant to Princeton University, in addition to funding provided by NICHD through the University of Michigan. Wave 5 was collected in 2009 by the Centre for Social Science Research (CSSR) at the University of Cape Town. Major funding for Wave 5 was provided by the Health Economics \& HIV/AIDS Research Division (HEARD) at the University of KwaZulu-Natal, with additional funding from the Andrew W. Mellon Foundation (through the CSSR at UCT), the European Union (through the Microcon research partnership on the micro-foundations of violent conflict, via the CSSR) and the NICHD (through the University of Michigan).

\section{Authors' contributions}

E.M and C.O conceived the idea. E.M performed data analyses, derived the models. All authors wrote the manuscript and provided critical feedback that shaped the manuscript.

\section{Conflict of interest}

None declared.

\section{References}

1. Lammers C, Ireland M, Resnick M, Blum R. Influences on adolescents' decision to postpone onset of sexual intercourse: a survival analysis of virginity among youths aged 13 to 18 years. The Journal of Adolescent Health: Official Pub- lication of the Society for Adolescent Medicine. 2000;26(1):42-8. 2. Baumgartner JN, Waszak Geary C, Tucker H, Wedderburn $\mathrm{M}$. The influence of early sexual debut and sexual violence on adolescent pregnancy: a matched case-control study in Jamaica. International Perspectives on Sexual and Reproductive Health. 2009;35(1):21-8.

3. Bearinger LH, Sieving RE, Ferguson J, Sharma V. Global perspectives on the sexual and reproductive health of adolescents: patterns, prevention, and potential. Lancet. 2007;369(9568):1220-31.

4. McHunu G, Peltzer K, Tutshana B, Seutlwadi L. Adolescent pregnancy and associated factors in South African youth. African Health Sciences. 2012;12(4):426-34.

5. Rutenberg N, Kaufman CE, Macintyre K, Brown L, Karim A. Pregnant or positive: adolescent childbearing and HIV risk in KwaZulu Natal, South Africa. Reproductive Health Matters. 2003;11(22):122-33.

6. Makenzius M, Larsson M. Early onset of sexual intercourse is an indicator for hazardous lifestyle and problematic life situation. Scandinavian Journal of Caring Sciences. 2013;27(1):20-6.

7. Hofferth SL, Kahn JR, Baldwin W. Premarital sexual activity among U.S. teenage women over the past three decades. Family Planning Perspectives. 1987;19(2):46-53.

8. Zuma K, Setswe G, Ketye T, Mzolo T, Rehle T, Mbelle N. Age at sexual debut: a determinant of multiple partnership among South African youth. African Journal of Reproductive Health. 2010;14(2):47-54.

9. Mazengia F, Worku A. Age at sexual initiation and factors associated with it among youths in North East Ethiopia. Ethiop J Health Dev. 2009;23(2).

10. UNAIDS. UNAIDS. The Prevention Gap Report. Joint United Nations Programme on HIV/AIDS. Geneva, Switzerland. 2016.

11. Panday S, Makiwane M, Ranchod C, Letsoalo T. Teenage pregnancy in South Africa - with a specific focus on school-going learners. Child, Youth, Family and Social Development, Human Sciences Research Council. Pretoria: Department of Basic Education. 2009.

12. Willan S. A Review of Teenage Pregnancy in South Africa, Partners in Sexual Health, 2013. 2013.

13. Cunningham PW, Boult BE. Black teenage pregnancy in South Africa: some considerations. Adolescence. 1996;31(123):691-700.

14. Taylor M, Jinabhai C, Dlamini S, Sathiparsad R, Eggers MS, de Vries H. Effects of a Teenage Pregnancy Prevention Programme in KwaZulu-Natal, South Africa. Health Care for Women International. 2014:0. 
15. Bhana D, Morrell R, Shefer T, Ngabaza S. South African teachers' responses to teenage pregnancy and teenage mothers in schools. Culture, Health \& Sexuality. 2010;12(8):871-83.

16. Marteleto L, Lam D, Ranchhod V. Sexual behavior, pregnancy, and schooling among young people in urban South Africa. Studies in Family Planning. 2008;39(4):351-68. 17. Clark S. Early marriage and HIV risks in sub-Saharan Africa. Studies in family planning. 2004;35(3):149-60.

18. Zheng AX, Anderson FW. Obstetric fistula in low-income countries. International Journal of Gynaecology and $\mathrm{Ob}$ stetrics: The Official Organ of the International Federation of Gynaecology and Obstetrics. 2009;104(2):85-9.

19. Gupta N, Mahy M. Sexual initiation among adolescent girls and boys: trends and differentials in sub-Saharan Africa. Archives of Sexual Behavior. 2003;32(1):41-53.

20. Oljira L, Berhane Y, Worku A. Pre-marital sexual debut and its associated factors among in-school adolescents in Eastern Ethiopia. BMC Public Health. 2012;12:375.

21. Klavs I, Rodrigues LC, Weiss HA, Hayes R. Factors associated with early sexual debut in Slovenia: results of a general population survey. Sexually Transmitted Infections. 2006;82(6):478-83.

22. Fatusi AO, Blum RW. Predictors of early sexual initiation among a nationally representative sample of Nigerian adolescents. BMC Public Health. 2008;8:136.

23. CDC. CDC, HIV/AIDS Surveillance Report, 1999, Atlanta:CDC, 2000. 2000.

24. Upchurch DM, Levy-Storms L, Sucoff CA, Aneshensel CS. Gender and ethnic differences in the timing of first sexual intercourse. Family Planning Perspectives. 1998;30(3):121-7.

25. Lee LK, Chen PC, Lee KK, Kaur J. Premarital sexual intercourse among adolescents in Malaysia: a cross-sectional Malaysian school survey. Singapore Medical Journal. 2006;47(6):476-81.

26. O'Donnell L, O'Donnell CR, Stueve A. Early sexual initiation and subsequent sex-related risks among urban minority youth: the reach for health study. Family Planning Perspectives. 2001;33(6):268-75.
27. Small SA, Luster T. Adolescent sexual activity: an ecological, risk-factor approach. J Marriage Fam. 1994(56):181-92.

28. Bronfenbrenner U. The Ecology of human development: Experiments by nature and design. Harvard University Press. 1979(Cambridge, MA:).

29. Bronfenbrenner U. Ecological research with children and families: From concepts to methodology. New York: Teachers College Press. 1988.

30. Appleyard K, Egeland B, van Dulmen MH, Sroufe LA. When more is not better: the role of cumulative risk in child behavior outcomes. Journal of child psychology and psychiatry, and allied disciplines. 2005;46(3):235-45.

31. Shisana O, Rehle T, Simbayi L, Parker W, Zuma K. South African National HIV prevalence, HIV incidence and behaviour and communication survey, 2008: a turning tide among teenagers? Cape'Town. HSRC Press. 2009. 32. Zuma K, Mzolo T, Makonko E. Determinants of age at sexual debut and associated risks among South African youths. African Journal of AIDS Research 2011;01/2011(10:189-194. ).

33. Gyan C. Effects of teenage pregnancy on the educational attainment of girls at Chorkor, a suburb of Accra. Journal of Educational and Social Research, 2013.

34. Pettifor A, O'Brien K, Macphail C, Miller WC, Rees H. Early coital debut and associated HIV risk factors among young women and men in South Africa. International Perspectives on Sexual and Reproductive Health. 2009;35(2):82-90. 35. Eaton L, Flisher AJ, Aaro LE. Unsafe sexual behaviour in South African youth. Social Science \& Medicine. 2003;56(1):149-65.

36. Harrison A, Smit J, Hoffman S, Nzama T, Leu CS, Mantell J, et al. Gender, peer and partner influences on adolescent HIV risk in rural South Africa. Sexual Health. 2012;9(2):178-86.

37. Dinkelman T, Lam D, Leibbrandt M. Linking Poverty and Income Shocks to Risky Sexual Behaviour: Evidence from a Panel Study of Young Adults in Cape Town. The South African Journal of Economics Suid-Afrikaanse Tydskrif Vir Ekonomie. 2008;76(supp1):s52-s74. 